\title{
CÉlULAS BINUCLEADAS NO NÚCLEO DO NERVO HIPOGLOSSO HUMANO ATRAVES DOS GRUPOS ETÁRIOS
}

\author{
Cecil José Rezze *
}

Durante muito tempo foi considerada como práticamente nula a capacidade de reprodução dos neurônios no sistema nervoso central de mamíferos adultos. Entretanto, desde fins do século passado vários trabalhos têm demonstrado a viabilidade da divisão de células nervosas diferenciadas.

Parece não haver dúvidas quanto ao aparecimento de células nervosas binucleadas e multinucleadas no sistema nervaso de vertebrados, particularmente de mamiferos, inclusive o homem. Os trabalhos de Rand e Courville $^{39}, 4^{40}$, Ivanovi26, Afanasiev e Kotovsky1 e Kirsche ${ }^{28}$ permitem considerar como definitivamente aceita a existência de tais células. Discute-se o seu significado, isto é, se estariamos diante de processo de divisão celular mitótica ou amitótica indicando regeneração de células nervosas diferenciadas ou indiferenciadas, ou se a divisão nuclear e nucleolar não indicaria apenas uma forma de defesa, sem chegar à divisão do citoplasma. Roussy e Mosinger ${ }^{43}$ admitem que a célula binucleada possa resultar da fusão de dois elementos uninucleados.

Células bi- e multinucleadas têm sido descritas no sistema nervoso do homem em determinadas doenças como neurossifilis (Spielmeyer ${ }^{46}$ ), atrofia muscular infantil (Greenfield e Stern ${ }^{18}$ ), em pacientes com sifilis (Lhermitte e Trelles ${ }^{35}$, Andrew ${ }^{4}$, Gerebtzoff ${ }^{15}$ ), na demência senil (Riese e Zfass $^{42}$ ), em casos de parkinsomismo conseqüente à encefalite letárgica e na paralisia agitante idiopática (Greenfield e Bosanquet ${ }^{19}$ ). Vários autores têm relacionado o aparecimento dessas células com o estímulo que de alguma forma essas doenças imprimiriam à divisão nuclear dos neurônios. Particularmente na sifilis tem sido apontada a toxina do treponema como a responsável pelo aparecimento de células binucleadas. Stigliani ${ }^{48}$ encontrou número expressivo destas células nos núcleos supra-óptico e paraventricular no hipotálamo de um homem que apresentava cirrose hepática. Assinala a divisão do núcleo por constrição e a posterior divisão de células que já apresentavam certos processos de necrobiose. O mesmo autor relata o encontro de células binucleadas, apenas uma ou duas, no hipotálamo do homem em outros processos patológicos e o mesmo no hipotálamo de cobaio, coelho e cão por êle estudados. Também Roussy e Mosinger ${ }^{43}$ descrevem células binacleadas no hipotálamo do homem, do cobaio e do cão. Botar encontra

Departamento de Anatomia Descritiva e Topográfica da Faculdade de Medicina da Universidade de São Paulo (Prof. Odorico Machado de Sousa): * Professor Assistente. 
cêrca de $1 \%$ de neurônios binucleados em gânglios simpáticos do homem, considerando-os como elementos jovens em divisão celular.

Em macacos inoculados com virus de poliomielite, Bodian ${ }^{8}$ encontrou neurônios bi- e multinucleados na substância reticular, em vários núcleos de nervos crânicos, na medula espinal e em gânglios espinais. Também Andrew $^{7}$, em macacos submetidos a virus mortos de poliomielite, encontrou células binucleadas em gânglios de plexos autônomos. Jaryguin ${ }^{27}$ comprovou a existência de células binucleadas no gânglio cervical superior de coelhos adultos e analisou a quantidade de RNA e DNA destas células concluindo que as mesmas não estavam em processo de divisão celular, salientando a necessidade de ser estudado seu verdadeiro significado citofisiológico.

Em animais desenvolveram-se estudos experimentais visando avaliar a capacidade de divisão dos neurômios. Os trabalhos vêm desde os fins do século passado e recentemente ganharam nôvo impulso com vistas aos problemas de regeneração do sistema nervoso em mamíferos. Pesquisadores, lesando partes do sistema nervoso (decorticação cerebral, aplicação local de substâncias irritativas ou inclusão de corpos extranhos), têm demonstrado divisão do núcleo produzindo células bi- ou multinucleadas sem divisão de citoplasma, divisão celular completa por processo mitótico ou amitótico. Neste sentido, os trabalhos de Schereiber e Wengler ${ }^{44}$, Grafova ${ }^{17}$, Gladky ${ }^{16}$, Afanasiev e Kotovsky ${ }^{1}$ documentam figuras de mitose em neurônios do córtex de ratos brancos. Kirsche ${ }^{28}$, estudando peixes e mamíferos, conclui que a divisão celular pode ser feita por mitose ou amitose, a partir de células diferenciadas ou indiferenciadas do sistema nervoso. Analisando as células binucleadas êste autor assinala que as mesmas não evolverão necessàriamente para uma divisão citoplasmática, assertiva já apresentada anteriormente por Jaryguin.

No homem o equivalente a essas pesquisas é o estudo das lesões traumáticas encefálicas e medulares. Gaupp ${ }^{14}$ reaviva o tema que já havia sido tratado por autores mais antigos. Rand e Courville ${ }^{39,40}$ encontram neurônios bi- e multinucleados próximos às margens da lesão, mesmo 17 anos após o traumatismo e, no caso de lesões antigas, embora prevalecessem as células binucleadas, ainda eram encontrados elementos multinucleados; a divisão nuclear era feita por uma constriç̧ão seguida da divisão total do núcleo, em neurônios diferenciados, que mostravam inicio de alterações necrobióticas; concluem os autores que a divisão citoplasmática não se efetua, sendo a multinucleação um processo positivo, porém abortivo, na recuperação celular. Para Rand e Courville, produtos originados de necrose ou alterações circulatórias poderiam desencadear a divisão nuclear, sendo tal agente inespecífico pois a multinucleação ocorre também nas imediações de hemorragias cerebrais intensas. Essse produto inespecífico não nos parece ser o fator de crescimento do sistema nervoso isolado por Levi-Montalcinis4 a partir do sarcoma 180 e 37, utilizado em suas experiências com embrião de galinha, porque em camundongos que tinham mais de 9 dias de idade esta autora não observou divisão celular, embora houvesse hipertrofia dos neurônios simpáticos. Courville ${ }^{10}$, estudando a ação do glioma maligno no encéfalo humano, encontra neurônios bi- ou multinucleados no córtex cerebral 
nas margens do tumor e explica o achado como uma alteração agônica transitória das células e não como uma degeneração neoplásica.

Em resumo, existem numerosos trabalhos, desde os que mostraram a simples existência de células binucleadas até aquêles que demonstram uma divisão celular completa de neurônios em indivíduos adultos. O tema avança para a regeneração do sistema nervoso central, salientando Ivanov ${ }^{26}$ a sua importância porque devemos estudar as causas que atuam na divisão neuronal e descobrir as condições que a propiciam; a negação apriorística do fenômeno regenerativo é um pretexto para não se pesquisar o assunto a fundo.

Compreende-se a importância do tema quanto às alterações que ocorrem na seniliadde, mormente quando consideramos os trabalhos de Inukai ${ }^{25}$, Loo $^{36}$ e Andrew2,5,6, que encontram células bi- e multinucleadas sòmente em animais velhos. Propuzemo-nos, então, a estudar estas possíveis modificações no homem, da infância à senilidade.

\section{MATERIAL E METODOS}

Foram utilizadas 26 medulas oblongas humanas retiradas de indivíduos brancos e masculinos, cujas idades variavam de 4 meses a 86 anos. A classificação dos individuos do ponto de vista étnico fol baseada nos caracteres somáticos externos essencials.

A fim de lograr homogeneidade na amostra excluimos os cadáveres de individuos com estados mórbidos que pudessem alterar especlficamente o número de células do sistema nervoso central ou de toda massa corporea (tumores cerebrais, amolecimentos cerebrais, meningites e meningencefalites, poliomielite, malformações congênitas ou adquiridas); excluimos também os casos de tumores em geral e os estados caquéticos por moléstias ou desnutriçăo. O elemento fundamental para o diagnóstico foi o exame anátomo-patológico complementado, quando possível, pelo estudo do prontuário de evoluçăo clínica.

O material era fixado em solucăo de tormol a $10 \%$, sendo a medula oblonga incluida em celoldina. Cortes serlados transversals (perpendiculares ao eixo anatômico do tronco encefálico) com $30 \mu$ de espessura foram corados pelo método de $\mathrm{Pal}$ -Weigert modificado por Erhart, sendo usado o picro-carmim para coloração de fundo.

o núcleo do nervo hipoglosso era localizado e, com aumento de 80 vézes, desenhávamos o contorno dos núcleos esquerdo e direito e seus subnúcleos. A seguir, com aumento de 320 vezes identificávamos os corpos celulares que eram contados desde que apresentassem citoplasma, núcleo e nucléolo evidentes. Contávamos separadamente as células do lado esquerdo e direito.

Em trabalho anterior (Rezze ${ }^{41}$ ), no qual utilizamos o mesmo material histológico, ftzemos a contagem integral do número de células em 9 casos $(3,5,6,17,18$, $19,23,24$ e 25). A partír dos dados assim obtidos, desenvolvemos cálculos estatísticos que nos permitiram usar uma em três secçōes, contando cêrca de um têrço do número de células de cada núcleo. Portanto, os demais casos não referidos acima estăo nestas condições.

Para o estudo das células binucleadas utillzamos aumento de 800 vêzes com objetiva de imersão. No mesmo corte em que a célula binucleada era encontrada faźamos mensuração dessa célula e de 10 outras al existentes. Avalíávamos os diâmetros maior e menor de cada corpo celular e de cada núcleo, medidos em sentido ortogonal. 
A análise estatística dos diâmetros das células uni- e binucleadas fol feita mediante comparação de médias usando a curva de "Student", a um nivel de significância de $5 \%$.

\section{RESULTADOS}

Encontramos 33 células binucleadas para um total de 202.910 células contadas, não havendo distribuiçāo preferencial delas em relação aos grupos etários (Quadro 1). As células binucleadas se diferenciavam das demais, fundamentalmente, pela apresentaçāo de dois núcleos cada um dos quais possuia um nucléolo. A forma do corpo celular tendia ao retângulo, ao losângo, à elipse e ao oval enquanto que as células uninucleadas, além destas, apresentavam, com freqüência, as formas estrelada, triangular e arredondada. Os caracteres do citoplasma, núcleo e nucléolo não diferiam entre as células uni- e binucleadas a não ser pelas dimensões. Assim, estas células mostravam-se com citoplasma bem corado, com grânulos de Nissl grandes, membrana nuclear evidente e nucléolo central ou ligeiramente excêntrico, corado em negro. Núcleo quase sempre elíptico podendo ser arredondado, por vêzes com a membrana nuclear enrugada. Não observamos núcleos lobados ou com outras indicaçōes de divisão amitótica ou mitótica. A cromatina era fina e rendilhada na sua distribuição dentro do núcleo.

As células de individuos com mais de 50 anos apresentavam depósito de pigmento de côr amarelada, a lipofucsina ou pigmento de uso. A deposição era tanto mais intensa quanto mais avançado o grupo etário, dando-se sob a forma de finos grânulos, diffceis de se identificar quando em pequena quantidade, fàcllmente visiveis quando êstes se reuniam formando conglomerados dentro do citoplasma. Este último mostrou aspecto de certa homogeneização em alguns individuos senis, com grânulos de Nissl menos evidentes. O nucléolo apresentou-se discretamente menos corável, aparecendo mais claro. Os vacúolos eram raros o que fazia supor a existência de um material retirado pelos solventes usados na técnica histológica. Dos caracteres descritos, apenas a deposição de lipofucsina era elemento privativo das idades mais avançadas, sendo que as demais alteraçōes também ocorreram em alguns individuos de idades mais baixas.

As células binucleadas de individuos senis apresentaram pequeno depósito de lipofucsina; não observamos qualquer vacúolo. Os demais caracteres já foram descritos.

O estudo estatístico confirmou a observação de que o corpo da célula binucleada era maior do que a uninucleada e que, inversamente, o núcleo de uma célula uninucleada era maior de que cada um dos núcleos da célula binucleada, embora a massa nuclear total da célula binucleada fôsse maior do que a massa nuclear de uma célula uninucleada. As células binucleadas tiveram os seguintes valôres médios para as dimensōes estudadas: diâmetro maior do corpo celular $39,8 \mu \pm 7,5$; diâmetro menor $23,7 \mu \pm 4,3$; diâmetro maior do núcleo $13,3 \mu \pm 2,7$; diâmetro menor $11,5 \mu \pm 1,5$. As células uninucleadas tiveram os seguintes valôres médios: diâmetro maior do corpo celular $33,9 \mu \pm 7,9$; diâmetro menor $22,1 \mu \pm 4,5$; diâmetro maior do núcleo $14,8 \mu \pm 3,3$; diâmetro menor $12,3 \mu \pm 2,5$.

Analisando os diâmetros obtidos mediante comparação de médias feitas a um nivel de significância de $5 \%$, cujo valor crítico é de $\pm 1,960$ na curva de "Student" no teste bicaudal, veriffcamos diferença estatisticamente válida entre os valôres observados com os seguintes resultados comparativos: do diâmetro malor do corpo celular entre células bi- e uninucleadas 4,245; do diâmetro menor 2,162; do diâmetro maior do núcleo entre células bi- e uninucleadas $-3,811$; do diâmetro menor $-\mathbf{3 , 4 7 8}$,

\section{COMENTARIOS}

Em nosso material, o pequeno número de células binucleadas ( $33 \mathrm{em}$ relação a 202.910 células contadas), sua distribuição indiferente pelos diver 


\begin{tabular}{|c|c|c|c|c|}
\hline \multirow{2}{*}{ Caso } & \multirow{2}{*}{ Idade } & \multicolumn{2}{|c|}{ Células } & \multirow{2}{*}{ Causa de morte e doenca } \\
\hline & & $b i-2$ & inucleadas & \\
\hline 1 & $4 \mathrm{~m}$ & $1 *$ & 4914 & Toxemia. Broncopneumonia. \\
\hline 2 & $6 \mathrm{~m}$ & $0^{*}$ & 5127 & $\begin{array}{l}\text { Toxemia. Otite purulenta. Colapso pulmo- } \\
\text { nar. }\end{array}$ \\
\hline $\mathbf{3}$ & $9 \mathrm{~m}$. & $1 * *$ & 15065 & Toxemia. Pneumonia lobar bilateral. \\
\hline 4 & 2 a. & $0^{*}$ & 4476 & Toxemia. Broncopneumonia. \\
\hline 5 & 4 a. & $2 * *$ & 14275 & Insuficiência cardiaca. Miocardite crônica. \\
\hline 6 & 5 a. & $3 * *$ & 14534 & $\begin{array}{l}\text { Toxemia. Leucemia aguda. Broncopneumo- } \\
\text { nia. }\end{array}$ \\
\hline 7 & 12 a. & $2 *$ & 3998 & Spticemia. Broncopneumonia abscedade. \\
\hline 8 & $20 \mathrm{a}$. & $0 *$ & 4342 & $\begin{array}{l}\text { Insuficiência renal. Cirrose hepática. Es- } \\
\text { quistossomose. }\end{array}$ \\
\hline 9 & 22 a. & $4 *$ & 5016 & $\begin{array}{l}\text { Toxemia. Atelectasia pulmonar. Fistula esô- } \\
\text { fago-bronquial. }\end{array}$ \\
\hline 10 & 28 a. & $0^{*}$ & 4553 & Insuficiência cardiaca. Miocardite crónica. \\
\hline 11 & 31 a. & $1 *$ & 5172 & $\begin{array}{l}\text { Broncopneumonia. Broncopneumonia con- } \\
\text { fluente. }\end{array}$ \\
\hline 12 & 37 a. & $0^{*}$ & 4708 & Toxemia. Broncopneumonia. \\
\hline 13 & $38 \mathbf{a}$ & $0^{*}$ & 4161 & $\begin{array}{l}\text { Anemia aguda. Cirrose de Läerinec. Olce- } \\
\text { ra gástrica. }\end{array}$ \\
\hline 14 & $41 \mathrm{a}$ & $0^{*}$ & 4458 & Toxemia. Tuberculose pulmonar. \\
\hline 15 & 47 a. & $5 *$ & 5297 & $\begin{array}{l}\text { Indeterminada. Hipertensão essencial be- } \\
\text { nigna. }\end{array}$ \\
\hline 16 & 47 a. & $1^{*}$ & 5105 & $\begin{array}{l}\text { Choque. Enfarte do miocárdio. Arterios- } \\
\text { clerose. }\end{array}$ \\
\hline 17 & 50 & $1 * *$ & 13925 & $\begin{array}{l}\text { Enfarte do miocárdio. Insuficiência car- } \\
\text { díaca. }\end{array}$ \\
\hline 18 & 52 a. & $\mathbf{3}^{* *}$ & 14561 & $\begin{array}{l}\text { Insuficiêncla cardiaca congestiva. Cor pul- } \\
\text { monale. }\end{array}$ \\
\hline 19 & 53 a. & $0 * *$ & 15031 & Toxemia. Broncopneumonia. \\
\hline 20 & $60 \mathrm{a}$. & $1 *$ & 4729 & $\begin{array}{l}\text { Toxemia. Pneumonia lobar. Trombose art. } \\
\text { femural. }\end{array}$ \\
\hline 21 & $62 \mathrm{a}$. & $1 *$ & 3988 & Toxemia. Pleuriz purulento. \\
\hline 22 & $63 \mathrm{a}$. & 1* & 4696 & Enfarte do miocárdio. Arteriosclerose. \\
\hline 23 & 70 a. & $2^{* *}$ & 11335 & Enfarte do miocárdio. Arteriosclerose. \\
\hline 24 & 76 a. & $0 * *$ & 12482 & $\begin{array}{l}\text { Insuficiencla cardiaca. Endocardite reuma- } \\
\text { tismal. }\end{array}$ \\
\hline 25 & 76 a. & $4 * *$ & 12032 & $\begin{array}{l}\text { Indeterminada. Hipertensão essencial be- } \\
\text { nigna. }\end{array}$ \\
\hline 26 & 86 a. & $0^{*}$ & 4930 & $\begin{array}{l}\text { Insuficiência cardiaca. Hipertensão essen- } \\
\text { cial benigna. }\end{array}$ \\
\hline Totais & & 33 & 202.910 & \\
\hline
\end{tabular}

Quadro 1 - Número de células uni-e binucleadas do núcleo do nervo hipoglosso humano (soma dos lados esquerdo $e$ direito) de 26 individuos brancos e masculinos de variados grupos etários: * contadas as células em uma de cada três seccões;

* contagem integral do número de células; $a .=$ anos; $m$. = meses. 

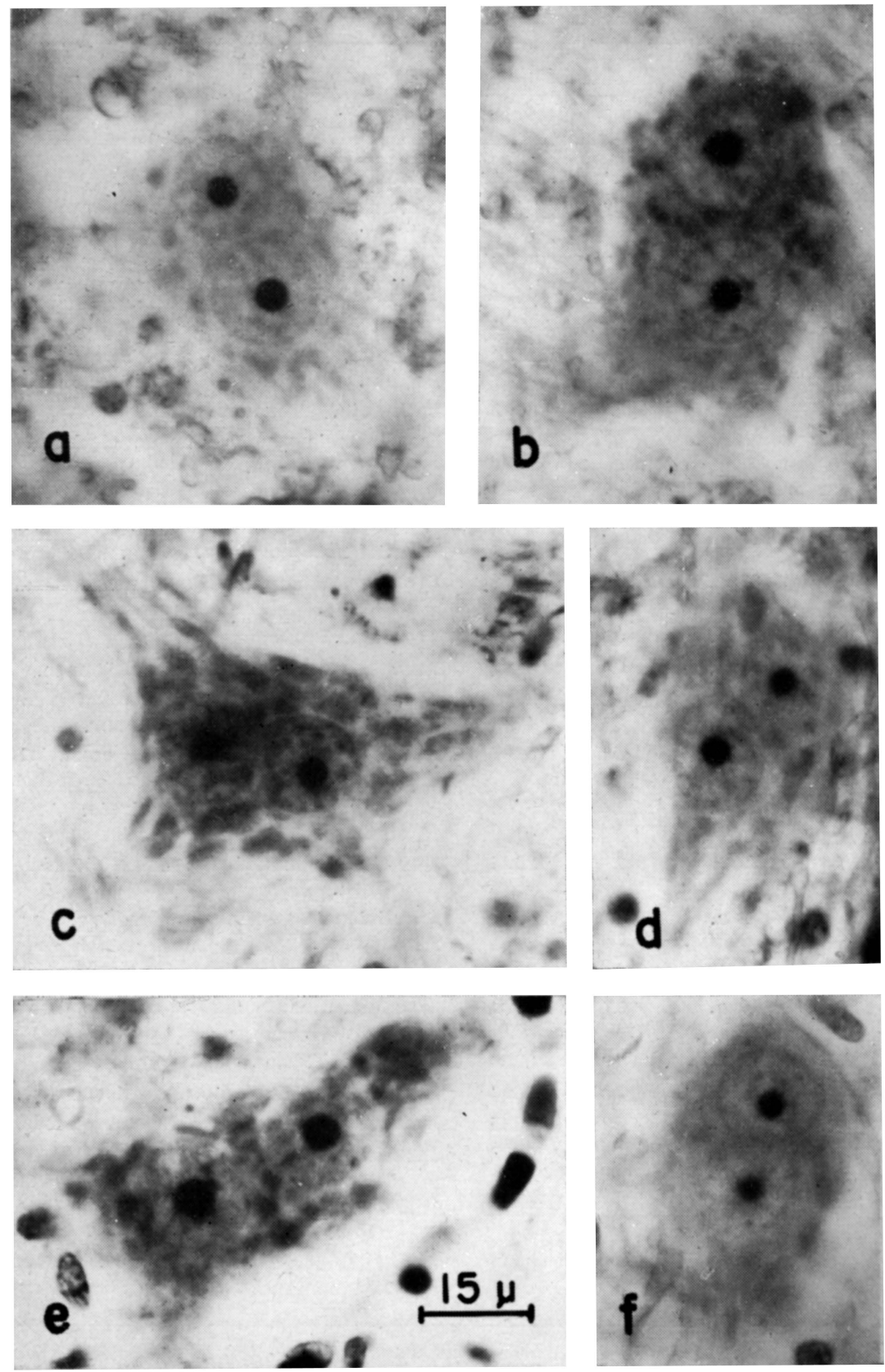

Fig. 1 - Células binucleadas e binucleoladas do núcleo do nervo hipoglosso humano. Método de Pal-Weigert modificado por Erhart, coloração de fundo picro-carmin. Fotografias obtidas com ocular $8 X$ e objetiva 100 com imersão. Individuos de: a) 47 anos; b) 60 anos; c) 5 anos; d) 52 anos; e) 4 anos; f) 60 anos: 
sos grupos etários e a ausência de figuras de reprodução mitótica ou amitótica leva à conclusão de que tais células não caracterizam um processo de involução senil. Além disso, nos grupos senís, os outros caracteres morfológicos das células binucleadas eram idênticos aos das células uninucleadas. O tamanho do citoplasma das células binucleadas em relação às uninucleadas e o tamanho maior de um de seus núcleos, mas os dois perfazendo um tamanho maior, não nos dão indicação de divisão celular; todos os demais caracteres são de células adultas diferenciadas, com corpúsculos de Nissl, núcleo, substância cromatínica fina e rendilhada e nucléolo evidentes.

As células binucleadas foram identificadas com bastante clareza (fig. 1). Por 14 vêzes tivemos certa dificuldade para distinguir entre figuras de superposição e células binucleadas. Movimentando o parafuso micrométrico com aumento de $800 x$, obtivemos a resolução adequada para classiricicá-las como figuras de superposição. A simples proximidade destas células, a nosso ver, não permite qualquer conclusão sôbre a possibilidade de terem elas provindo da divisão de uma célula binucleada. Mesmo que a hipótese fôsse levantada não teríamos qualquer indicação sôbre a idade em que o fato se deu. Ressalte-se que o pequeno número de dúvidas, bem como a distribuição indiferente pelos diversos grupos etários, não alteraram as conclusões.

Comparando nossos resultados com aquêles constantes na literatura, devemos assinalar os que se referem a células bi- e multinucleadas em individuos senis. Assim, Andrew ${ }^{6}$, tendo encontrado figuras de divisão mitótica, conceitua o fenômeno de reação no qual uma das características é a multinucleação da célula nervosa em idades avançadas. Inukai ${ }^{25}$ e Loo $^{36}$, trabalhando em ratos albinos, e Andrew ${ }^{2,5}$, com camundongos, encontram a multinucleação apenas em animais velhos. Entretanto, Wilcox ${ }^{51}$, em 26 cobaios de várias idades, encontra apenas uma célula que julga ter núcleo multilobado. Salientemos que o próprio Andrew3, 4 não encontrou, no homem, células binucleadas no velho, só o fazendo em um indivíduo de 22 anos com neurossifilis. Lhermitte e Trelles ${ }^{35}$ referem o encontro de células binucleadas em um indivíduo de 70 anos, com o diagnóstico histopatológico de sífilis. Portanto nestes dois casos havia uma causa já estudada por outros autores, ou seja, a ação da toxina do treponema sôbre a divisão nuclear.

Nossas observações estão de acôrdo com os achados de Andrew que, no homem, não encontrou células binucleadas caracterizando o processo de senilidade. Também devemos assinalar que vários autores, estudando as alterações citológicas relacionadas com a senilidade no sistema nervoso, não referem o encontro de células bi- ou multinucleadas (Hodge $^{23}$, Manouélian $^{38}$, Kuntz $^{32}$; Léri ${ }^{33}$, Ellis ${ }^{11,12}$, Harms ${ }^{20,}{ }^{21}$, Spiegel ${ }^{45}$, Sjövall ${ }^{47}$, Kiss ${ }^{29}$, Maleci $^{37}$, Gardner $^{13}$, Truex ${ }^{49}$, Truex e Zwemer50, Kuhlenbeck ${ }^{30,}$, ${ }^{51}$, Hopker ${ }^{24}$, Wright e $\operatorname{Spink}^{52}$ ).

É necessário observar que nossa amostra foi colhida de forma a evitar doenças que atuassem no sistema nervoso produzindo alterações celulares morfológicas e quantitativas. Por êste fato é que explicamos as pequenas variaçōes citológicas entre os grupos adulto e senil sendo, a nosso ver, o depósito de lipofucsina o único caráter essencial nessa diferenciação. Quanto 
às células binucleadas, podemos salientar que a amostragem foi colhida de forma a evitar indivíduos com estados mórbidos que sabidamente determinam o aparecimento de tais elementos.

Encontramos pequeno número de células binucleadas não caracterizando qualquer grupo etário em particular. O significado biológico de nossos achados continua no campo das hipóteses, mas parece claro que as potencialidades celulares serão iguais sob o ponto de vista qualitativo, para os grupos etários estudados, embora quantitativamente não tenhamos meios para avaliação. As células binucleadas não estavam apresentando reprodução nuclear ou celular e o significado morfofuncional destas células continua a desafiar a argúcia dos pesquisadores.

\section{RESUMO}

Foram contadas e estudadas as células uni- e binucleadas do núcleo do nervo hipoglosso humano de 26 indivíduos brancos e do sexo masculino, com idades variando entre 4 meses a 86 anos, todos sem processos patológicos que presumìvelmente determinassem alterações nas células nervosas. Os cortes seriados com $30 \mu$ de espessura, foram corados pelo método de Pal Weigert modificado por Erhart, sendo feita coloração de fundo pelo picro-carmim. Mediante comparação dos diâmetros medidos ortogonalmente foi verificado, pelo estudo estatístico, que as células binucleadas eram maiores que as uninucleadas.

O pequeno número de células binucleadas (33 em 202.910 células contadas), sua distribuição indiferente nos diversos grupos etários e a ausência de figuras de reprodução mitótica ou amitótica, levam à conclusão de que a sua presença não caracteriza um processo de involução senil.

O significado dêste achado que tem sido atribuído a processo de divisão celular mitótica ou amitótica, à divisão nuclear ou nucleolar sem chegar à divisão citoplasmática ou à fusão de duas células uninucleadas, é discutido à luz dos dados constantes da literatura.

\section{SUMMARY}

Binucleated nerve cells in the human nucleus n. hypoglossi through ages

It has been generally accepted that mature neurons of the central nervous system of adult mammals are incapable of cell-division. Nevertheless, recent data are suggesting the contrary. Mature neurons, bi- or multinucleated, observed in the central nervous system of vertebrates, mammals and man are being differently interpreted: as a result of mitotic or amitotic cell-division of mature neurons; as indiferentiated cells which could indicate a regeneration process; as a cellular reaction to nervous injuries; as the result of the fusion between two mononucleated elements.

The cells of the human nucleus $n$. hypoglossi were counted an studied in 26 white males, the youngest four months old, the eldest, eightysix years old. The material secured at the necropsy table was selected in order to exclude diseases or physical conditions which could interfere with the final results. 
The medulla oblongata were formalin fixed, imbedded in celloidin, $30_{\mu}$ serial cross sectioned, numbered and stained by Pal-Weigert modified by Erhart method for myelin sheaths. The counterstain was by carmin.

The cells were counted when their cell-bodies showed evident nucleus and nucleolus. They were measured and carefully analysed including with high magnification.

From the 202.910 counted cells, 33 were binucleated. These latter did not present any characteristic of mitotic or amitotic cell-division an no relation between age and higher frequency of binucleated cells could be observed.

The general morphology of the binucleated cells was equivalent to the mononucleated ones although the former were significantly larger than the latter. The statistical analysis was made by comparision of sample mean of two populations at the five per cent level of significance.

It is concluded, considering the studied material and the current literature, that there is no reason to accept, the presence of binucleated nerve cells as a biological reaction due to old age. The real significance of these cells is still unknown, but it can be admitted that they should have a biological capacity which would be qualitatively the same in the differente ages. Nevertheless, their quantitative evaluation is not possible, as far as we know.

\section{REFERENCIAS}

1. AFANASIEV, Y. I. \& KOTOVSKY, E. F. - To the question of cerebral neuron division in mammals. Path. Biol. 9:880, 1961. 2. ANDREW, W. - The effects of fatigue due to muscular exercise on the Purkinje cells of the mouse, with special reference to the factor age. $z$. Zellforsch. 27:534, 1937. 3. ANDREW, W. - The Purkinje cell in man from birth to senility. $Z$. Zellforsch. $28: 292,1938$. 4. ANDREW, W. - Origin and significance of binucleate Purkinje cells in man. Arch. Path. 28:821, 1939. 5. ANDREW, W. - Amitotic division in senile tissues as a probable means of self preservation of cells. J. Geront. 10:1, 1955. 6. ANDREW, W. - Structural alterations with aging in the nervous system. In Neurologic and Psychiatric Aspects of Disorders of Aging. Res. Publ. Ass. nerv. ment. Dis. 35:129. William \& Wilkins Co., Baltimore, 1956. 7. ANDREW, W. - Evidence for the division of nuclei and cell bodies of neurons of autonomic ganglia in adult mammal. An. Fac. Med. Montevideo. 44:191, 1959. 8. BODIAN, D. - Multinucleated neurons in Macaca mulatta. Anat. Rec. 91:267, 1945. 9. BOTAR, J. - Recherches qualitatives et quantitatives sur les cellules nerveuses du ganglion coeliaque de l'homme. C.R. Ass. Anat. 42è Reéun. :1441, 1955. 10. COURVILLE, C. B. - Multinucleation of cortical nerve cells at margin of malignant glioma. J. Neuropath. exp. Neurol. 15:369, 1956. 11. ELLIS, R. S. - A preliminary quantitative study of the Purkinje cells in normal, subnormal and senescent human cerebella, with some notes on functional localization. J. comp. Neurol. 30:229, 1919. 12. ELLIS, R. S. - Norms for some structural changes in the human cerebellum from birth to old age. J. comp. Neurol. 32:1, 1920. 13. GARDNER, E. - Decrease in human neurons with age. Anat. Rec. 77:529, 1940. 14. GAUPP, R. - Zweikernige Ganglienzellen in traumatischen Hirndefekten. Z. ges. Neurol. Psychiat. 149:122, 1933. 15. GEREBTZOFF, M. A. - De la multinucleation dans les neurons du système nerveux central. Acta Neurol. belg. 53:234, 1953. 16. GLADYK, A. P. - Amitotic division of nerve cells. Arch. Anat. Histol. Embriol. 35:59, 1958 (Russ). 17. GRAFOVA, G. J. - Nerve-elements of the spinal cord system; their reactive changes in damage. Arch. Anat. Histol. Embriol. 34:67, 1957. (Russ). 18. GREENFIELD, J. G. \& STERN, M. B. - The anatomical identify of the Werdnig-Hoffmann and Oppenheim forms of infantile muscular atrophy. Brain. 50:652, 1927. 19. GREENFIELD, J. G. \& BOSANQUET, F. D. - Brain stem lesions in parkinsonism. J. Neu- 
rol. Neurosurg. Psychiat. 16:213, 1953. 20. HARMS, W. - Morphologische und experimentelle Untersuchungen analternden Hunden. Z. Anat. Entwickl. Gesch. 71:340, 1924. 21. HARMS, W. - Alterserscheinungen im Hirm von Affen und Menschen. Zool. Anz. 75:249, 1927. 22. HATAI, S. - Number and size of the spinal ganglion cells and dorsal root fibers in the white rat at different ages. J. comp. Neurol. 12:107, 1902. 23. HODGE, C. F. - Changes in ganglion cells from birth to senile death. Observations on man and honey bee. J. Physiol. 17:129, 1894. 24. HOPKER, W. - Das altern des nucleus dentatus. Z. Forsch, 5:256, 1951. 25. INUKAI, T. On the loss of Purkinje cells with advancing age from the cerebellar cortex of the albino rat. J. comp. Neurol. 45:1, 1928. 26. IVANOV, I. F. - Present state of the problem of division of differentiated neurons. Arch. Anat. Histol. Embriol. 38:89, 1960 (Russ). 27. JARYGUIN, U. N. - On binucleated nerve cells in sympathetic superior cervical ganglion in rabbit. Arch. Anat. Histol. Embriol. 47:77, 1964. (Russ). 28. KIRSCHE, W. - Regenerative Vorgänge im Gehirn und Rückenmark. Ergebn. Anat. Entwickl. Gesch. 38:141, 1965. 29. KISS, F. - Senile und experimentelle Verändernungen an den Zellen der peripherischen Ganglien. Beitr. path. Anat. 92:127, 1933. 30. KUHLENBECK, H. - Seniles changes in the brains of Wistar Institute rats. Anat. Rec. 88:441, 1944. 31. KUHLENBECK, H. Some histologic age changes in the rat's brain and their relationship to comparable changes in the human brain. Confin. neurol. (Basel). 14:329, 1954. 32. KUNTZ, A. - Histological variations in autonomic ganglia and ganglion cells associated with age and disease. Amer. J. Path. 14:783, 1938. 33. LERI, A. - Le cerveau senile. Rev. Neurol. 14:756, 1906. 34. LEVI-MONTALCINI, E. - Growth control of nerve cells by a protein factor and its antiserum. Science, 143:105, 1964.35 . LHERMITTE, J. \& TRELLES, J. O. - La dégénération hypertrophique des cellules de l'olive bulbaire chez le veillard. Rev. neurol. 57:618, 1932, 36. LOO, Y. T. Thymonucleic acid in Purkinge cells. J. comp. Neurol. 67:423, 1937. 37. MALECI, O. - Contributo alla conoscenza delle variazioni quantitative delle cellule nervose nella senescenza. Arch. ital. Anat. Embriol. 33:883, 1934. 38. MANOUÉLIAN Y. Des lésions des ganglions cérébro-spinaux dans la vieillesse. C. R. Soc. Biol. Paris. 55:115, 1903. 39. RAND, C. W. \& COURVILLE, C. B. - Histologic changes in the brain in cases of fatal injury to the head. Arch. Neurol. Psychiat. 55:80, 1946. 40. RAND, C. W. \& COURVILLE, C. B. - Multinucleation of cortical nerve cells at the margins of traumatic lesions of the human brain. J. Neuropath. exp. Neurol. 6:1, 1947. 41. REZZE, C. J. - Sôbre o número de células do núcleo do nervo hipoglosso humano através dos grupos etários. Fol. Clín. et Biol. 34:31, 1965.42. RIESE, W. \& ZFASS, I. S. - Cerebral cortex of a man with senile dementia bellieved to be 107 years old. Arch. Neurol. Psychiat. 51:78, 1944. 43. ROUSSY, G. \& MOSINGER, Ni. - Sur la plurinucleose neuronale dans les noyaux végétatifs de l'hypothalamus des mammifères. C. R. Soc. Biol. 118:736, 1935. 44. SCHEREIBER, L. \& WENGLER, L. - Ueber Wirkungen des Scharlachöls auf die Netzhaut Mitosenbildung der Ganglienzellen. Zbl. allg. Path. path. Anat. 19:529, 1908. 45. SPIEGEL, A. - Ueber die degenerativen Veränderungen in der Kleinhirnrinde im Verlauf des Individualzyklus vom Cavia cobaya Marcgr. Zool. Anz. 79:173, 1927. 46. SPIELMEYER, W. - Histopathologie des Nervensystems. Julius Springer Verlag, Berlim, 1922. vol. 1, pp. 43 e 455. 47. SJOVALL, E. - Die Bedeutung der altersveränderungen im Zentralnervensystem. Verh. anat. Ges. (Jena). 41:37, 1932. 48. STIGLIANI, R. - Sul reperto di divisioni diretti nelle cellule gangliari dell'ipotalamo dell'uomo e degli animali. Boll. Soc. ital. Biol. sper. $34: 452,1958$. 49. TRUEX, R. - Morphological alterations in the gasserion ganglion cells and their association with senescence in man. Amer. J. Path. 16:255, 1940. 50. TRUEX, R. R. \& ZWEMER, L. R. - True fatty degeneration in sensory neurons of the aged. Arch. Neurol. Psychiat. 48:988, 1942. 51. WILCOX, H. H. - The structural changes in the nervous system related to the process of aging. In BIRREN, J. E.; IMUS, H. A. \& WINDLE, W. F. - The process of Aging in the Nervous System. Charles C. Thomas, Springfield (Illinois), 1959. p. 16. 52. WRIGHT, E. A. \& SPINK, J. M. - A study of the loss of nerve cells in the central nervous system in relation to age. Gerontologia (Basel). 3:277, 1959.

Departamento de Anatomia (Descritiva e Topográfica). Faculdade de Medicina da Universidade de São Paulo. Caixa Postal 2921. São Paulo SP - Brasil. 